\title{
ALCARAZ: INTRIGAS Y MANDO A DISTANCIA EN LA ÉPOCA DE LAS COMUNIDADES DE CASTILLA
}

\section{ALCARAZ: CONSPIRACY AND OUTSIDE INTERFERENCE IN THE DECADE OF THE 1520 INSURGENCY}

EDWARD COOPER

Real Academia de Alfonso X el Sabio

Murcia, España

slovatt1@btinternet.com

Cómo citar este artículo: Cooper, E. (2021). Alcaraz: intrigas y mando a distancia en la época de las Comunidades de Castilla. Al-Basit (66), 5-45. http://doi. org/10.37927/al-basit.66_1

Recibido/Received: 30-11-2020

Aceptado/Accepted: 26-02-2021

RESUMEN: La interpretación del levantamiento en 1520 de las Comunidades de Castilla se suele concebir en base a divisiones horizontales, reales o imaginadas, de la sociedad de Castilla. El análisis de algunos centros de subversión, en particular Zamora, Murcia, Requena, Cuenca, Plasencia, Baeza y otros, ha demostrado que, ocurriera lo que ocurriera en la calle, los protagonistas estuvieron influenciados y hasta apoyados por los mismos intereses creados desde fuera, motivados por el deseo de mantener el control de los recursos económicos. Es decir, las divisiones en la sociedad que imperaban eran tanto verticales como horizontales. Este estudio identifica estos intereses en el caso de Alcaraz, aunque, al final, que se sepa, no hubo en la ciudad
ABSTRACT: In the interpretation of the rising in 1520 of the Comunidades de Castilla, the tendency has been to view the events within the framework of a stratification in Castilian society, real or imagined. Analysis of some flashpoints of insurgency, in particular Zamora, Murcia, Requena, Cuenca, Plasencia, Baeza and others, has shown that, whoever was involved in street skirmishes, the protagonists were often influenced and even supported by the same vested interests from elsewhere, apprehensive of the prospect of losing control of economic resources. That is to say, the relevant divisions of society were as much vertical as horizontal. This study identifies such interests in Alcaraz, although, as it turned out, the expected clashes 
las manifestaciones violentas que se preveían (como en otros lugares falta la documentación para las establecer fechas precisas).

PALABRAS CLAVE: Comunidades, intereses creados, Alcaraz, duque de Alba, Adelantado Mayor de Murcia, Gonzalo Chacón, conde de Paredes, marqués de los Vélez, Medina del Campo, Hernando Gamarra, grana. did not materialise there, as far as is known (as elsewhere there is a gap in local records).

KEYWORDS: Vested interests, Alcaraz, duke of Alba, lord lieutenant of Murcia, Gonzalo Chacón, count of Paredes, marquis of los Vélez, Hernando Gamarra, Medina del Campo, Kermes.

Como otros municipios económicamente boyantes en Castilla a finales de la Edad Media, la ciudad de Alcaraz seguía siendo susceptible a los altibajos políticos y a las presiones de los intereses creados. Estos han sido resumidos, con el debido soporte documental, para dos épocas de fuertes reacciones en varios lugares del reino, en particular la muerte de Felipe de Borgoña (Felipe I de España, el 25 de septiembre de 1506 (Pretel, 1976, p. 3), y la rebelión de las Comunidades de Castilla (1520-1522) (Pretel, 1977). La interpretación inevitablemente selectiva del autor en cuestión hace caso omiso de ciertas anomalías consideradas tal vez de importancia marginal, pero que siguen exigiendo una explicación.

La derrota del segundo marqués de Villena en la Guerra de Sucesión de los Reyes Católicos no puso fin definitivo a la codicia señorial de los recursos de Alcaraz. El marqués intentó reestablecerse al menos en Chinchilla. La estadística poblacional de Alcaraz en las primeras dos décadas del siglo XVI parece estable y hasta podríamos hablar de un aumento ${ }^{1}$. Su término territorial era desproporcionado. Hacia el norte llegaba hasta Villarrobledo, una distancia de casi $100 \mathrm{kms}^{2}$ Fue dotado de Fuero propio por Alfonso X y, posible-

\footnotetext{
${ }^{1}$ Hay frecuentes solicitudes de avecindamiento por forasteros, normalmente aceptadas, en esta época. Sobre el papel, el atractivo más importante tuvo que ser la franqueza alcaraceña del repartimiento del servicio, aunque los corregidores solían cumplir con las demandas de la Corona.

${ }^{2}$ Villarrobledo fue vendido al marquesado de Villena en 1469, pero no cesó por eso la influencia de Alcaraz en el entorno.
} 
mente como resultado indirecto, el alcance de su corregimiento era de una amplitud poco usual. Alcaraz era probablemente también único en ser a la vez arcedianato y arciprestazgo, jurisdicciones en la diócesis de Toledo no del todo congruentes, pues la autoridad del arcediano cubría el santiaguista Campo de Montiel.

Aunque el terreno del término de Alcaraz no se prestaba al pastoreo intensivo, tiene suficientes salinas, cruciales para la alimentación de los animales en la trashumancia, las más importantes situadas en Pinilla y Salobre. Entre Pinilla y Alcaraz pasa la Cañada Real de los Serranos, o de Extremadura a Cuenca, que tiene su origen en la Sierra de Albarracín. Se une cerca de Salobre con la Cañada Real de Andalucía o de los Valencianos, para seguir hacia la Sierra de Segura. Otro recurso mineral alcaraceño fue una mina de alumbre, dada a Diego López de Haro, tío del primer marqués de Villena, por la princesa Isabel en $1468^{3}$. Más allá de ser término de Alcaraz, se desconoce su localización. Sin embargo, al ser en ese año alcaide de Riópar, aldea de Alcaraz con una fortaleza formidable, Juan Alfonso de Haro y Acuña, hijo de Diego López (Ayllón 2008)4, esta dependencia de Alcaraz es más que probable. Durante la Guerra de Sucesión, los Haro y Pedro Fajardo Quesada, Adelantado Mayor de Mur-

\footnotetext{
${ }^{3}$ Real Academia de Historia Colección Salazar M45 fol. 303 (en adelante RAH Salazar). Al citar en 1991 esta fuente, ignorábamos a Morales, 1987, que reproduce el texto de otra versión que obra en el archivo del ducado de Alba. Es evidente que se trataba de una iniciativa seria, aunque infructífera debido probablemente a la carencia de infraestructura entre Alcaraz y el punto más cercano de la comercialización, en ese momento Valencia.

${ }^{4}$ El topónimo El Puntal de la Mina, una altura que domina Salobre, también puede referirse a los alumbres. Una alusión poco explícita trata sobre otro mineral: rrelacion del bol arménico que lo ve Juan de Bustamante (Archivo Municipal de Alcaraz Legajo 317 exp. 22: acta del 9 de septiembre de 1506. He utilizado la versión en internet de Actas y Series Documentales del Archivo Municipal de Alcaraz bajo el LRU:

http://iealbacetenses.dipualba.es/results.vm?o=\&w=alcaraz $\& \mathrm{f}=\& \mathrm{~s}=0 \& \mathrm{~g}=$ work $\&$ c=0\&lang=es\&view=docs Las citas de este fondo a continuación AMA y la signatura de archivo, que hace más fácil la consulta).

En España se conocen existencias en Jumilla (Altoplano Murciano/marquesado de Villena) y Fortuna (Murcia Oriental). Es poco probable que se confunda con el alumbre, aún en esa época.
} 
cia, copropietario con el marqués de Villena de derechos mineros en el reino de Murcia, se encontraron en bandos opuestos, siendo Alcaraz el escenario de las hostilidades. Parece ser que Juan Alfonso perdió sus derechos a ostentar propiedades en Alcaraz, aunque posteriormente logró recuperar el ascendiente.

Riópar, sin embargo, quedó en manos del segundo conde de Paredes, tras un prolongado asedio que le brindó, según las tradiciones bélicas de la época, el derecho de conquista (Pretel, 1976 (2), 17-19. El manejo de la fuente sobre la acción bélica es magistral). A los de Alcaraz les parecía un truco:

[...] no resultó difícil al conde de Paredes hacer creer a los Reyes [Católicos] que la toma de Riópar había sido una acción inspirada por la fidelidad manriqueña, en lugar de presentarlo... como una de tantas empresas militares aisladas que las banderías nobiliarias de la belicosa familia habían hecho emprender..., siempre ansiosos de acrecentar sus dominios.

Sobre Riópar no iba a haber margen para el compromiso. Alcaraz perdió un recurso esencial para su pujante industria textil, y el conde ganó una recompensa vital por el despoblamiento endémico en sus dominios en la zona.

Otro recurso de que disponía el término de Alcaraz fue la grana, el colorante usado en la industria textil, tanto la lanera como la sedera, derivado de los quermésidos que infestan el chaparro. Su extracción fue manzana de la discordia en muchas localidades en los años prósperos de la industria pañera en Castilla, desde el último cuarto del siglo XV hasta el segundo del XVI, y también en zonas de conflicto en la rebelión de las Comunidades de Castilla. Según Diego de Sotomayor, regidor de Alcaraz, una fuerza de hasta 200 hombres armados, procedentes de la Roda, Minaya, Villarrobledo, San Clemente y el Provencio, invadieron el alfoz de Alcaraz en el otoño de 1510 «para coger grana» (Sánchez Ferrer, 1987, p. 369).

No se limitaron así las intervenciones de forasteros en los asuntos de Alcaraz, según se desprende de este documento inédito: 
yo el príncipe enbio mucho saludar a vos el concejo justicia rregidores caualleros escuderos oficiales et omes buenos de la noble my cibdad de Alcaras mis vasallos como aquellos de quien mucho fio: fago vos saber que a mi es fecha rrelacion del buen deseo et lealtad que aveys mostrado e mostrays a lo que cunple a my seruycio e guarda de esa dicha my cibdad e lugares e fortalesas de su tierra disiendo que vos era fecho entender que yo quería enajenar e apartar de my señorío esa dicha my cibdad e su tierra et las fortalezas de ella et que vosotros mouydos con buen celo et leal propósito por guardar e conservar la dicha my cibdad e tierra e fortalezas para mi e para mi seruycio vsando de la lealtad e fidelidad que me deuedeis posisteis grand rrecabdo en la guarda de ella e de las dichas fortalezas e tierra con grandes trabajos e gastos de vuestras personas e fasiendas et como quier que aquellas cosas que asy vos fueron fechas entender no eran ny son verdaderas pero acatando vuestro deseo ser bueno et leal a my seruycio et que vos mouysteis a ello con buen celo et leal propósito guardado la lealtad et fidelidad que asy me deuedeis yo vos he tenido e tengo en seruycio agradable vuestro buen deseo et leal voluntad por lo que vos entiendo onrrar ayudar e faser merced como a buenos et leales vasallos como quiera que syn ser bien certificados de tal fecho non deuierades faser los mouimyentos et escándalos que a my es dicho que posisteis en obra por que vos mando a todos e a cada vno de vos que luego vista la presente cesedes e vos dexedes de faser los dichos mouymientos et escándalos e de aquí adelante vos non entremetades a los faser ny poner en obra syn causa porque segund dicho es las tales cosas no fueron ny son verdaderas ny aquella fue ny es my entencion salvo tener e guardar e mandar guardar e defender para my esa dicha my cibdad e fortalezas e tierra de ella e de la no enajenar ny apartar de my señorío segund el bachiller Iohan Martines Guerrero vos dira de mi parte al qual vos mando dedes conplida fe e creencia a faser cosas que el de my parte e aquellas pongays en obra segund de vosotros confio. De la villa de Alcala de Henares a ix días de mayo ROTO et por que acerto de lo sobre dicho vos ove inbiado decir ciertas cosas con el comendador Alfon de Almaras las quales creo ya avreys sabido 


\section{et aquella es la verdad e my voluntad. Yo vos mando aquello se ponga en obra en la manera que vos lo asy enbie mandar}

Yo el Principe

Por mandado del príncipe Alonso de Rribera ${ }^{5}$

Falta el año, pero una minuta del concejo de Alcaraz fechada el 23 de mayo de $1497^{6}$ corrobora la entrega del documento por Gonzalo de Badajoz, mensajero del Príncipe Juan, primogénito de los Reyes Católicos y, desde 1496, señor de Alcaraz y de una nutrida selección de poblaciones apropiadas para un principe de Asturias. No hay referencia a la frase que hemos resaltado (en negrilla) o al detalle crucial del involucramiento de Alfonso Almaraz, comendador de la Magdalena, incondicional ${ }^{7}$ del duque de Alba, dando a entender un encubrimiento. La misma existencia de este documento demuestra que el siempre pujante duque de Alba se había inmiscuido en la corte del príncipe ${ }^{8}$. No figura el comendador de la Mag-

\footnotetext{
${ }^{5}$ Archivo del Marquesado de Valdeguerrero, sin clasificar. Los últimos 3 renglones del documento figuran en una tinta distinta y parecen haber sido añadidos después de la finalización del texto. A Gonzalo de Badajoz no se caracterizó especialmente por su honestidad (Archivo General de Castilla (Simancas) - Registro General del Sello noviembre de 1494 fol. 256. En adelante AGC Sello etc.). El 30 de octubre de 1496 el Príncipe, de forma autónoma, había confirmado al conde de Paredes la posesión de Riópar (Pretel 1976 (2)). Es algo que el duque hubiera rechazado si hubiera sido posible.

${ }^{6}$ AMA legajo 14, expediente 8.

${ }^{7}$ De todas maneras, lo había sido del primer duque, García Álvarez de Toledo, fallecido en 1488, y cabe suponer que seguía siéndolo para su sucesor, Don Fadrique (Cooper, 1991: 164-166).

${ }^{8}$ Es notable la ausencia del padre del duque tanto en el bautismo del príncipe en Sevilla el 9 de julio de 1478 como en su juramento como heredero de la corona de Castilla y León en las Cortes de Toledo de 1480. En su formación impera un equilibrio entre el dominico Diego de Deza, catedrático y obispo de Salamanca, y el franciscano fray García de Padilla, moderado, si fuera posible, por Pedro Mártir de Anglería (Rodríguez Sánchez, 2001, pp. 22-48). El príncipe era inteligente y responsable, pero su debilidad física le hizo ser la diana de las intrigas de los magnates locales. La inclusión de Salamanca en el listado de los señoríos cedidos al príncipe marca inequívocamente el monopolio ducal de la confianza del regio vástago, facilitado seguramente por Diego de Deza, en cuya casa en Salamanca iba a morir el príncipe. En su testamento dejó iguales cantidades en efectivo a fundaciones dominicas y franciscanas, reflejando la experiencia educativa de su infancia.
} 
dalena en ningún cargo administrativo de la Corona, por lo tanto, su presencia no es por algún asunto estatal. Bien pudieron temer los alcaraceños que el Príncipe, ya señor de Salamanca, pensaba pasar Alcaraz al duque.

Lo que pudo precipitar la gestión es la noticia ${ }^{9}$ de que Alonso Ruiz de Solís comendador (santiaguista) de Villanueva de la Fuente, había anexionado terreno de la ciudad a su torre de Gorgojí, crucialmente ubicada para entorpecer el paso de los rebaños serranos entre la Mancha y la Andalucía jiennense. Dicho comendador no hubiera podido actuar de esta manera sin la aprobación, teóricamente, del gobernador del Campo de Montiel y las Sierras, y probablemente del comendador de Montiel, encomienda principal de la Orden de Santiago, situada a menos de $20 \mathrm{kms}$. de distancia. El titular de Montiel en ese momento era Gonzalo Chacón, contador mayor y mayordomo de los Reyes y del Príncipe. En 1481 su segundogénito, Juan Chacón, había adquirido la mitad del monopolio en la explotación de los alumbres de Murcia, además del Adelantamiento Mayor de Murcia, al casarse con la sobrina del segundo conde de Paredes, Luisa Fajardo Manrique, legataria tanto de la dignidad como del negocio (una auténtica «rica hembra» de su época). Con el transcurso del tiempo, el despegue del comercio de los alumbres en manos del Adelantado iba a hacer que su derrocamiento fuera el objetivo principal de la política ducal. Este asunto es el trasfondo de todas las circunstancias que se narran a continuación.

El doble desposorio, algo prematuro, de Magdalena Manrique, hija del conde de Paredes, con el hermano mayor del Adelantado, otro Gonzalo Chacón, y de la hermana de éste con el futuro tercer conde de Paredes (enlace que sí se realizó), acordado el 10 de diciembre de 1491, siendo todos los desposados menores de edad ${ }^{10}$,

Es al príncipe que se debe la iniciación del empedrado de las calles tanto de Salamanca como de Alcaraz, realizado años después.

${ }^{9}$ Minuta de acta municipal del 14 de febrero de 1497 (AMA legajo 14 exp. 8). Alonso Ruiz es consuegro del $3^{\text {er }}$ conde de Paredes (Losa Serrano, 2015 p. 95).

${ }^{10}$ Real Academia de Historia loc.cit. fols. 80v.-82. 
proclamaba lo estrecha que era la fusión ${ }^{11}$ Chacón/Manrique. En abril de 1497, el Adelantado se había encontrado sentado al lado del conde de Medellín en las nupcias del Príncipe y Margarita de Austria, celebradas en Burgos y presididas por el duque, consuegro desde hacía tres años de este conde (Cooper, 2019, 41). La coyuntura no fue seguramente casual, y transmitió al duque una señal de advertencia, pues el conde de Medellín, por estar cargado de deudas, era un eslabón débil en la hegemonía ducal en Extremadura, y el enlace condal con el duque era crucial para mantenerlo (Cooper, 1991, ap. doc. 290 ${ }^{12}$. Hubiera sido una calamidad para este si su consuegro hubiera tomado por fiador al Adelantado.

El Príncipe moriría el 4 de octubre. Que se sepa no insistió el comendador de Villanueva en seguir ocupando Gordojí pero, frente a la desaparición del real vástago, el duque no pudo quedarse de brazos cruzados. Tampoco desapareció el obstáculo para sus ambiciones levantado por el Adelantado, quien, en 1493 volvió a casarse, tras dos años de viudez, con la hija del segundo conde de Paredes, sobrina de su propia suegra. Este refuerzo del poderío de los Chacón/Manrique fue igualado dos años más tarde: Huéscar, centro de crianza del "cordero segureño», fue enajenado, no a este conde, que lo codiciaba, sino al de Lerín, el condestable de Navarra, para llegar en 1513 a manos del mismo duque. Ventaja aplazada, pues la impenetrable endogamia de los Chacón no pudo hacerse más explícita que con otro desposorio, probablemente también en 1497,

\footnotetext{
${ }^{11}$ Lo que consolidó el enlace de la casa de Paredes con la de los Adelantados fue seguramente la decisión en 1475 del primer conde, siendo Maestre de Santiago, de desposeer a Juan Alonso de Haro de la encomienda de Caravaca y transferirla a su recién nacido nieto Juan Fajardo hijo del Adelantado Pedro Fajardo (Torres Fontes, 1953: 122). El conde moriría al año siguiente y el niño comendador dos años después.

${ }_{12}$ Tal vez solo el duque supiera lo débil que era realmente el eslabón. Leonor de Toledo, su hija bastarda, casada con el heredero del conde, era progenie del duque con su propia cuñada, Mayor Solís y Toledo, esposa de García de Toledo y Enríquez (Boase, 2017: p. 179). El matrimonio del duque, y el de su hermano, aguantó, pero el enlace con los Puertocarrero era de utilidad estrictamente temporal para el duque. Conseguido un nieto para el conde, Leonor de Toledo fue retirada del compromiso ya indigno para casarse en 1504 con el $3^{\text {er }}$ conde de Alba de Liste.
} 
del hijo del Adelantado (el futuro marqués de los Vélez) con la antedicha Magdalena Manrique, ya hermana de su madrastra.

El patrimonio del conde de Paredes en la sierra de Alcaraz, apodado «las cinco villas», origen de repetidos pleitos con la ciudad sobre jurisdicciones, seguía siendo una verdadera maniobra envolvente sobre el realengo alcaraceño, sobre todo al quedar apuntalado por la ciudadela que era Riópar. El duque se hubiera dado cuenta de que en 1501 el cura de la iglesia de Bogarra, en plena Sierra de Alcaraz, era Juan Soriano, canónigo de la catedral de Cartagena (i.e. Murcia). Su detentación in absentiam de este modesto beneficio era más importante que lo que por sí misma parecería, al ser probablemente pariente de Gil Sánchez Soriano, arcipreste de Chinchilla y tesorero del cabildo catedral de Murcia, patriarca de toda una dinastía nepotista de clérigos titulares de múltiples beneficios. Se debe también a Gil Sánchez el disfrute por el arcediano cartagenero de Lorca, Francisco de Onteniente (otro absentista), de un beneficio en la iglesia de la Trinidad de Alcaraz (Ayllón, 2009, pp. 95-110) ${ }^{13}$.

Pudo parecer entonces que el duque no tenía con qué abrir la más mínima brecha en la red familiar que le hacía frente, pero una grieta iba abriéndose espontáneamente a partir de 1490. Desavenencias en las filas de los Chacón crecieron sobre la posesión del castillo de Casarrubios del Monte (la Sagra), fastuosa obra conjunta de Don Gonzalo y el Adelantado.

\footnotetext{
${ }^{13}$ En un capítulo cartagenero de 1507, Juan Soriano parece votar por una medida aprobada por el hijo del Adelantado, pronto a ser marqués de los Vélez (Cooper, 2019 , p. 80). Es de suponer que los beneficiados de las iglesias del alfoz de Alcaraz correspondientes a la diócesis de Cartagena, como el Bonillo, eran allegados del marqués de los Vélez/Adelantado Mayor de Murcia. Aunque falleciera hacia 1513, Gil Sánchez, dedicado durante toda su vida a un tráfico transnacional de prebendas, dignidades e inmuebles, pudo poner a disposición del marqués de los Vélez una red íntegra de presbíteros sumisos en diversas diócesis, válida seguramente diez años más tarde.

La salina de Bogarra es importante para los rebaños transeúntes de la sierra de Alcaraz.
} 


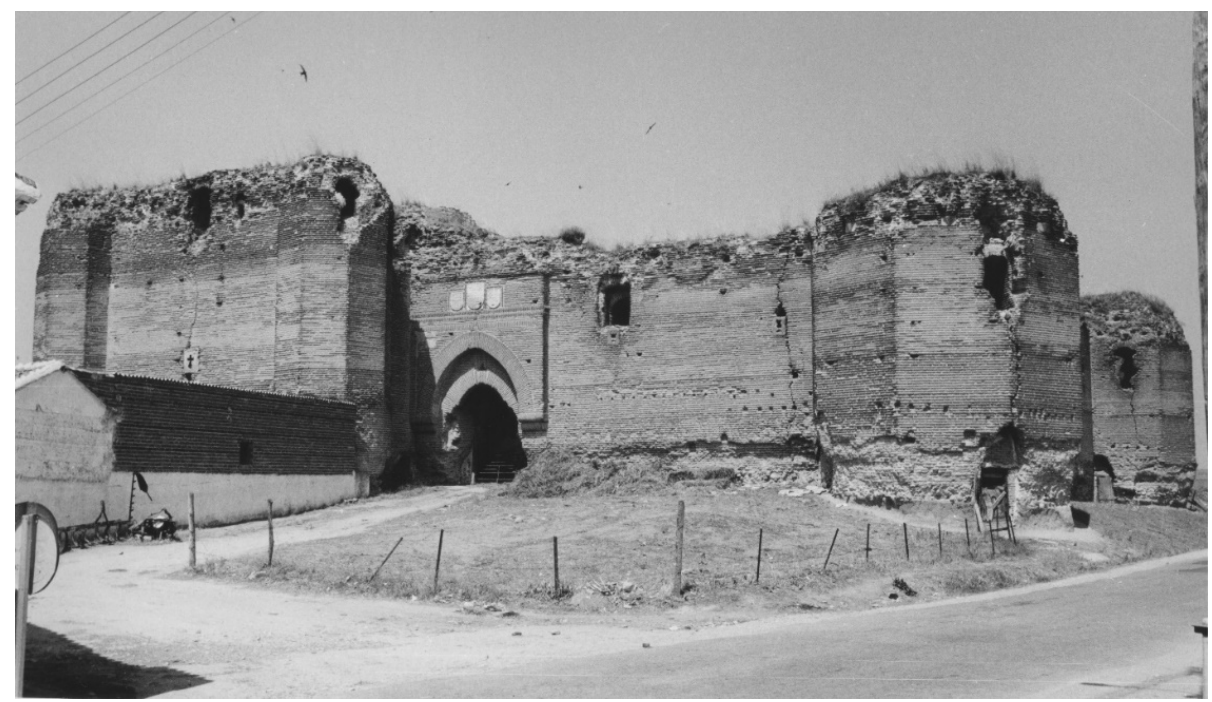

Casarrubios del Monte (la Sagra): el castillo en 1966 (E.Cooper).

En 1499 el anciano Gonzalo volvió a casarse en segundas nupcias con otra Manrique emparentada, pero no tan estrechamente, con sus tocayos ya mencionados. La dama evidentemente una cazafortunas, metió sus mesnadas en el castillo para evitar que pasara a la progenie de su marido. El Adelantado hizo que la Corona enviara a Hernando Gamarra, comendador de Sagra y Cenete, a tomar el castillo en abril de 1501 (no hay el más mínimo indicio de que la situación fuera un ardid del duque, aunque es lícito sospecharlo).

El fallecimiento del mismo Adelantado, el 4 de abril de 1503, no puso fin a los contenciosos de los Chacón. Se cambiaron simplemente los litigantes. La viuda la parte demandante, y el acusado, el hijo de su marido por el primer matrimonio. El duque pensaría tener controlada la situación sin involucrarse públicamente, pues el marido de Magdalena Manrique, heredero del Adelantamiento (con el patrimonio murciano) se encontraba con las compañías de su ejército en el Rosellón. La Corona no tuvo prisa ninguna en resolver la disputa sobre un castillo inacabado, que pronto iba a ser una ruina irrecuperable, pues el proceso iba a durar un cuarto de siglo (Cooper, 1991, pp.185-186). En este tiempo el tercer conde 
de Paredes, Rodrigo Manrique, cuñado del nuevo Adelantado Pedro (Chacón) Fajardo, era todavía menor de edad pues quien gestiona los pleitos en nombre del condado es su madre, Leonor Acuña.

Por sí sola la ocupación de Gorgojí en 1497 no pudo ser de tanta importancia como para atraer una intervención ducal. Más en relación al caso fue seguramente una circunstancia originada dos años antes, a primera vista un simple trámite. Se trataba del traslado a la Mitra de Cartagena en febrero de 1495 de Juan Ruiz de Medina, obispo de Badajoz. Hasta 1499 no se personó siquiera en su nueva diócesis, dejándola en manos de dos prebendados de Astorga, su anterior sede, Alfonso de Mariana arcediano de Páramo, y su mayordomo Alfonso García del Rincón, abad de Compludo (Rodríguez Llopis, 1994, p. 64). Como el obispo, Alfonso García era también oriundo de Medina del Campo.

Al morir Juan Ruiz en 1507, siendo obispo de Segovia, Alfonso García pensaba que ganaría la elección al título de Abad de Medina del Campo. De hecho, hubo empate, y estalló entonces una lucha de bandos entre éste y el prior de Sevilla, un tal Bernardino Gutiérrez, para hacerse con la dignidad (el derecho pretendido por Gutiérrez le correspondió seguramente porque Juan Ruiz había sido canónigo de Sevilla). En el transcurso de las hostilidades era evidente que los partidarios de Gutiérrez eran allegados del duque de Alba (Cooper, 1991, ap. doc. 314), lo cual hace sospechar que, en 1495, para Juan Chacón era extraordinariamente conveniente tener en Alfonso García un contacto importante en Medina Campo, centro del comercio internacional del alumbre ${ }^{14}$.

Prevaleció en la abadía de San Antolín en Medina del Campo Alfonso García del Rincón. No terminó seguramente así la asociación con el Adelantado de Murcia. Entre 1516 y 1523 el abad dotó la colegiata de San Antolín de una obra conmemorativa (Campo, 2005,

\footnotetext{
${ }^{14}$ La primera coincidencia de uno apellidado Rincón con los Adelantados de Murcia, es del escribano de cámara Alfonso Rincón, que redactó un contrato en 1485 entre Juan Chacón y diversos interesados en la gestión, precisamente, del alumbre (Franco, 1980, p.244). Desde luego, puede ser una simple coincidencia.
} 
pp. 385-408). No es especialmente suntuosa, pero podemos adivinar por su evidente solvencia que procedia del bolsillo del marqués de los Vélez. Tampoco desapareció el prior de Sevilla, que seguía titulándose Abad de Medina del Campo. Hasta su fallecimiento en el último cuarto de 1520, es difícil saber a cuál de ellos se refiere la simple frase «abad de Medina del Campo» (De La Peña, 2017, p. 358 ${ }^{15}$. El autor de la fuente de los datos es menos suspicaz que nosotros: dadas las condiciones del tiempo, y la persona que era el prior, no es improbable que fuera asesinado. El prior endosó la suspensión del pago de las rentas reales de Medina del Campo, acto que le colocó al lado de los sublevados. El motivo pudo ser simplemente quitarle apoyo popular a García del Rincón. Pero, al hacerlo, se hubiera apartado del mandato del duque de Alba. Consecuencias imprevisibles.

Al haberle sido tomada la delantera, el proceder de Alfonso García ha de reflejar la postura del marqués de los Vélez, de no incriminarse, como el resto de Medina del Campo, donde, no obstante, «durante los dos años siguientes» (a 1518) «el sistema comercial de ventas al fiado - obligaciones notariales de pagar de feria en feria - sufrió una quiebra total» (Álvarez García, 1986, p.477). De hecho, la villa de las ferias se mantuvo inicialmente libre del desasosiego social que se centraba sobre todo en las ciudades representadas en Cortes. Hasta se celebró la feria de mayo de 1520, mediante una garantía otorgada por la administración del cardenal Adriano a los comerciantes. Los medinenses respondieron disociándose de la agitación anti-fiscal «que Satanás ha levantado en estos reinos» (Álvarez García, 1986, pp. 480-481).

Todo cambia con el incendio de Medina del 21 de agosto de 1520. El rencor de Antonio Fonseca, el principal responsable, consuegro, recuérdese, del duque de Alba, es primordial; sus motivos, menos aparentes. La intención declarada: hacerse con la artillería

\footnotetext{
${ }^{15}$ Otra fuente fecha su desaparición, erróneamente creo, en los últimos meses de 1521, pero coincide con nosotros en sospechar un asesinato (Álvarez García, 1986: 563).
} 
medinense, es tal vez secundaria, a la luz de la referencia despreciativa del exceptuado Luis de Quintanilla a las «quatro bocas de fuego que avia en Medina» (De la Peña, 2017, p. 362). A nivel personal, primaba en la sicología de Fonseca el hecho de que le había sido prohibido levantar la torre del homenaje de su castillo de Coca. Por la base actual de la torre, se puede imaginar que la posible altura alcanzada hubiera permitido no solo ver la torre del homenaje de la Mota de Medina, sino incluso el pueblo entero, hasta una distancia de $34 \mathrm{~km}$ en la llanura ${ }^{16}$.

Tal vez más reveladores son los daños colaterales del incendio: centrados en el asolado convento de San Francisco, «el incendio llevó a los mercaderes a la quiebra» (Álvarez García, 1986, p. 491). Destaca entre los perjudicados Álvaro de Bracamonte, vecino de Ávila, importante exportador medinense de textiles, condenado por exceptuado del perdón general de los comuneros y posteriormente (¡tres años después!) absuelto (Fernández Martín, 1993, p. 103). Parece que era uno de los diecinueve hijos bastardos inéditos de Álvaro Dávila Bracamonte, nieto de Inés Fajardo Quesada, tía del abuelo del marqués de los Vélez. Varias fuentes genealógicas pretenden identificar a esta Inés como progenie de una generación anterior, aseveración imposibilitada por el segundo apellido.

Sin tener conexión visible con la artillería de Medina, ni ser siquiera avecindado en Medina, Bracamonte se encontró como blanco explícito de los incendiarios de Antonio Fonseca. Perdió probablemente cantidad de stock, lo mismo que hubiera sufrido el marqués de los Vélez al mantener en Medina existencias de alumbres para comerciar ${ }^{17}$. Otro damnificado fue el Doctor Francisco Pérez de Var-

\footnotetext{
${ }^{16}$ Se deduce de la estructura existente. No consta un embargo específico sobre la torre de Coca, pero la suspensión de la obra no iba a deberse a insuficiencia económica del acaudalado Fonseca.

${ }^{17}$ Lo que queda fuera de toda duda: el 6 de diciembre de 1518, delante de Diego González de Santillana, notario medinense, una compañía de mercaderes de Burgos se compromete a pagar al marqués 3.000.000 de maravedís por una cantidad de alumbre (Carvajal, 2015: asiento 6243). En 1486 el quintal de alumbre valía en la feria de Medina del Campo unos 350 maravedís (Igual, 2014: nota 79). Sin duda variaba el precio, tanto como la calidad de la mercancía: mutatis mutandis
} 
gas, empresario de las minas de alumbre de Rodalquilar (Almería) (Fernández Martín, 2015, p. 100). La actividad económica del abad fue la compra de deudas. El incendio habría destruido la garantía colateral de los deudores y con ello su capacidad de amortizar. Se puede deducir que, de ser en principio ecuánimes frente a los rebeldes, en una sola jornada el marqués, Bracamonte, Alfonso García del Rincón, que protagoniza el asedio de Alaejos ${ }^{18}$, y posiblemente el doctor Pérez de Vargas, se convirtieran en sus partidarios. El abad de Medina y Compludo iba a morir en 1523, habiendo visto su casa en Medina ocupada por una sobrina de Antonio Fonseca y su marido Rodrigo Mexía ${ }^{19}$.

La tumultuosa llegada del nuevo Adelantado a la ciudad del Segura el 16 de diciembre de 1503 había disipado cualquier ilusión que el duque pudiera albergar de que Murcia iba a ponerle la alfombra roja. Ya el 23 de junio los hombres de Pedro Fajardo habían secuestrado a la adinerada heredera Leonor de Guevara del monasterio murciano de la Madre de Dios, fundación (en 1490) del Deán de Cartagena Martín de Selva ${ }^{20}$. El motivo fue entorpecer el matri-

se puede pensar que el marqués entregó algo como 800 toneladas del producto, suficiente para el cargamento de diez navíos en los muelles de Bilbao. La producción anual acordada en 1485 entre Juan Chacón y los empresarios de sus minas fue 4.000.000 quintales (Franco, 1980: p. 244).

Del mismo escribano es un protocolo del 13 de junio de 1519, que registra una deuda de Alfonso García del Rincón al mercader Gregorio de Medina (Carvajal, 2015, asiento 5361) que es acreedor también de Francisco Pérez de Vargas (Carvajal, 2015: asiento 2111). De estos valiosísimos fondos, pese a la industria de Carvajal de la Vega y su equipo, deben faltar muchas referencias. No figura, por ejemplo, Álvaro de Bracamonte y del marqués de los Vélez hubiera debido haber más de una sola cita.

${ }^{18}$ Probablemente la mayor acción militar de los rebeldes (Cooper, 1991: p. 135).

${ }^{19}$ Figura en 1522 entre los exceptuados del Perdón General otorgado a los comuneros identificados (se le nombra en el documento «Don Alonso Hernándes abbad de Compludo y de Medina», claramente un error de la letra del original y no de Pérez, como pretende de la Peña). Sus familiares se ocuparon de la recuperación de sus bienes confiscados por la Corona. Al principio del dilatado proceso de averiguación de su culpa fue alojado en el convento de San Antonio de la Cabrera, naturalmente franciscano (de la Peña, 2017, p. 369).

${ }^{20}$ El documento que sirve de fuente culpa directamente a Pedro Fajardo, pero estaba todavía en el Rosellón. 
monio, aparentemente forzado, de la dama con Juan Hurtado de Mendoza y Arroniz, vecino de Murcia. Leonor de Guevara es nieta de Juan Alfonso Fajardo Mendoza, primo del abuelo del Adelantado. El oficial designado para resolver el conflicto, el juez de residencia Diego Romaní, fue denunciado por allegado del Adelantado, y la Corona no tenía más recurso que suspenderle, con lo que parece haber sido la facción del Adelantado en el Regimiento de Murcia.

El futuro del licenciado Romaní pendía de una balanza: tras haber servido durante al menos una década como procurador fiscal en todo el territorio castellano, estaba frente a la ruina. Parece totalmente ilógico que, siendo oficial respetado y solvente, pudiera llegar a sacrificar su posición profesional por un compromiso con Pedro Fajardo, poco favorable para personas de origen converso. La única explicación plausible es el parentesco de su cuñada, Beatriz Ordóñez de Villaquirán, casada con el hijo de Aldonza Fajardo, nieta de un tío del suegro de Juan Chacón. El marido de Aldonza Fajardo, además, era hermano del primer conde de Paredes, abuelo de Luisa Fajardo. En marzo de 1504, emplazado para personarse delante del Consejo Real, y temeroso de la justicia de la Corona, el licenciado se refugió en el monasterio de San Francisco de Murcia (Gomariz, 2000, docs. 494, 497, 560, 566, 619).

No se duda la histórica afinidad del marquesado de los Vélez con la orden franciscana:

Los promotores de las fundaciones (franciscanas) son en estos momentos (siglos XVI-XVII), por la regla general, los Concejos que en los lugares de señorío han de contar con la autorización de los señores territoriales, en este caso los marqueses de los Vélez, tradicionales protectores de la provincia franciscana de Cartagena, ampliamente también por sus dominios murcianos (Torres Fernández, 1997, pp. 281-282) ${ }^{21}$.

${ }^{21}$ Inevitablemente, el convento de San Luis obispo en Vélez Blanco, fundado en 1599 por el $4^{\text {to }}$ marqués, es franciscano. Era evidente que Juan Chacón había querido fomentar el franciscanismo en Murcia, aunque tropezó con ciertos obstáculos políticos (Meseguer, 1972). 
Originariamente, el patrocinio de los frailes viene de los Manrique de Lara, más bien que de los Chacón o los Fajardo, en particular de las Clarisas ${ }^{22}$ y del monasterio de la Consolación de Calabazanos (Cerrato), a donde se retiró Magdalena Manrique después de su divorcio del primer marqués. Allí habría encontrado a las dos hijas menores del matrimonio de Juan Chacón con Inés Manrique, y a la abadesa Aldonza Manrique, hermana del $3^{\text {er }}$ conde de Paredes.

Los enlaces demuestran la fuerza de la endogamia en esta época en manos de quien como Pedro Fajardo, decidiera explotarla, aunque, en el caso del licenciado Romaní, no eran especialmente estrechos. La protección franciscana del licenciado en Murcia era la de los Fajardo/Manrique. Es poco probable que le valiera de modo permanente. Se puede especular incluso que Diego Romaní debía su oficio en primer lugar a la influencia del mismo Juan Chacón. Tenía además su propia conexión con los frailes. El primer marido de su suegra, el converso Antón Núñez de Ciudad Rodrigo, contador mayor de Enrique IV, a quien no pudo conocer, había sido partidario del Rey de Portugal en la guerra de la sucesión de los Reyes Católicos ${ }^{23}$. Fue perdonado cuando murió en 1479, pero sus bienes quedaban

\footnotetext{
${ }^{22}$ Preferido notablemente por las mujeres de la familia Manrique (Montero, 1996, pp. 329-330).

${ }^{23}$ La persona clave en la reconstrucción de la genealogía de los Ordóñez de Villaquirán es la suegra del licenciado. Hay dos indicios de su segundo matrimonio, hasta ahora indocumentado. Una hija, cuñada del licenciado, se llama Catalina Ordoñez de Guzmán, y no de Villaquirán. El otro es el hecho que tenía dos hijas llamadas Isabel Ordóñez. La mujer del licenciado no incluye lo de Villaquirán. La otra hija, al desposarse con Bernardino Manrique, era beneficiaria de un mayorazgo que su madre formó en 1487 de lo que había podido salvar del patrimonio de su primer marido. La hermana de esta afortunada, evidentemente la segundona, se casó con Pedro Pacheco, primo de Antonio Acuña, obispo de Zamora.

Los Villaquirán a finales del siglo XV habían llegado a formar principalmente tres grupos, de Ciudad Real, de Salamanca y de Zamora. Los de Salamanca eran partidarios del Rey de Portugal en la guerra de la sucesión de los Reyes Católicos, siguiendo probablemente el ejemplo del suegro del licenciado Romaní. Los de Zamora se mantuvieron firmes. Parece que el obispo de Oviedo, Valeriano Ordóñez, era de esta rama. El tutor de su progenie fue el Deán de Zamora, Diego Vázquez de Cepeda. Esta coyuntura puede explicar cómo pudo conseguir Lucas de Tauste una canongía en el cabildo ovetense (Cooper, 2019, 96).

Para la confección de la tabla genealógica he hecho uso de AGC Sello marzo de 1487 fol. 1, y RAH Salazar M6 fols. 252-3.
} 
en gran parte en manos del duque de Alba. Fue enterrado en el convento de San Francisco de Salamanca, lo cual pudo ser el comienzo de orientación de los frailes hacia los oponentes del duque. Una cuñada del licenciado, Francisca Ordóñez, era monja en las Clarisas de Santa Marina en Zamora.

El empeño en la devoción franciscana no tenía un origen del todo espiritual: el enlace del padre del marqués de los Vélez con Luisa Fajardo había sido un compromiso político urdido por la Reina Católica. El momento crucial fue el día del fallecimiento de Juan Chacón, el 4 de julio de 1503. Sabiendo la Reina que el supuesto mayorazgo de Cartagena se tambaleaba al borde de la invalidez, con tan solo ganar la carrera para llegar primero al puerto pudo dictar las condiciones del acceso del futuro marqués al rico legado del Adelantado. Se había frenado la intervención de sus tías, hermanas de su difunta madre: precisamente una de ellas, Catalina Fajardo y Manrique, había sido persuadida a aceptar la regla de San Francisco en el monasterio de Santa Clara de Murcia, beneficiario así mismo de la magnificencia de Luisa Fajardo, y las otras dos fueron compensadas de una forma u otra (García Díaz, 1989, p.158). La hermana del marqués, Isabel Fajardo, murió en 1509, y fue enterrada vestida con el hábito franciscano (como la misma Reina en el convento franciscano de Granada) en la iglesia de Santa Olalla de Paredes de Nava.

El secuestro era en esta época el estilo del nuevo Adelantado de Murcia. A principios de 1504 instigó el del mismo deán de Cartagena (Cooper, 1991, ap. doc. 274). No podemos pensar que careciera de conexión con el asunto de Leonor Guevara, ni que fuera ajeno a otra acción piadosa del Deán, también de 1490, la dotación al embrionario convento dominicano en Murcia de los terrenos necesarios para su fundación. Tanto el nuevo Adelantado como su padre hubieran conocido el estrecho patrocinio de la orden dominicana por el duque de Alba. Subrayó la posibilidad de una conspiración contra el Adelantado, en beneficio del duque, un atentado del hermano del Deán contra los contratistas del alumbre del Adelantado Juan Chacón. 


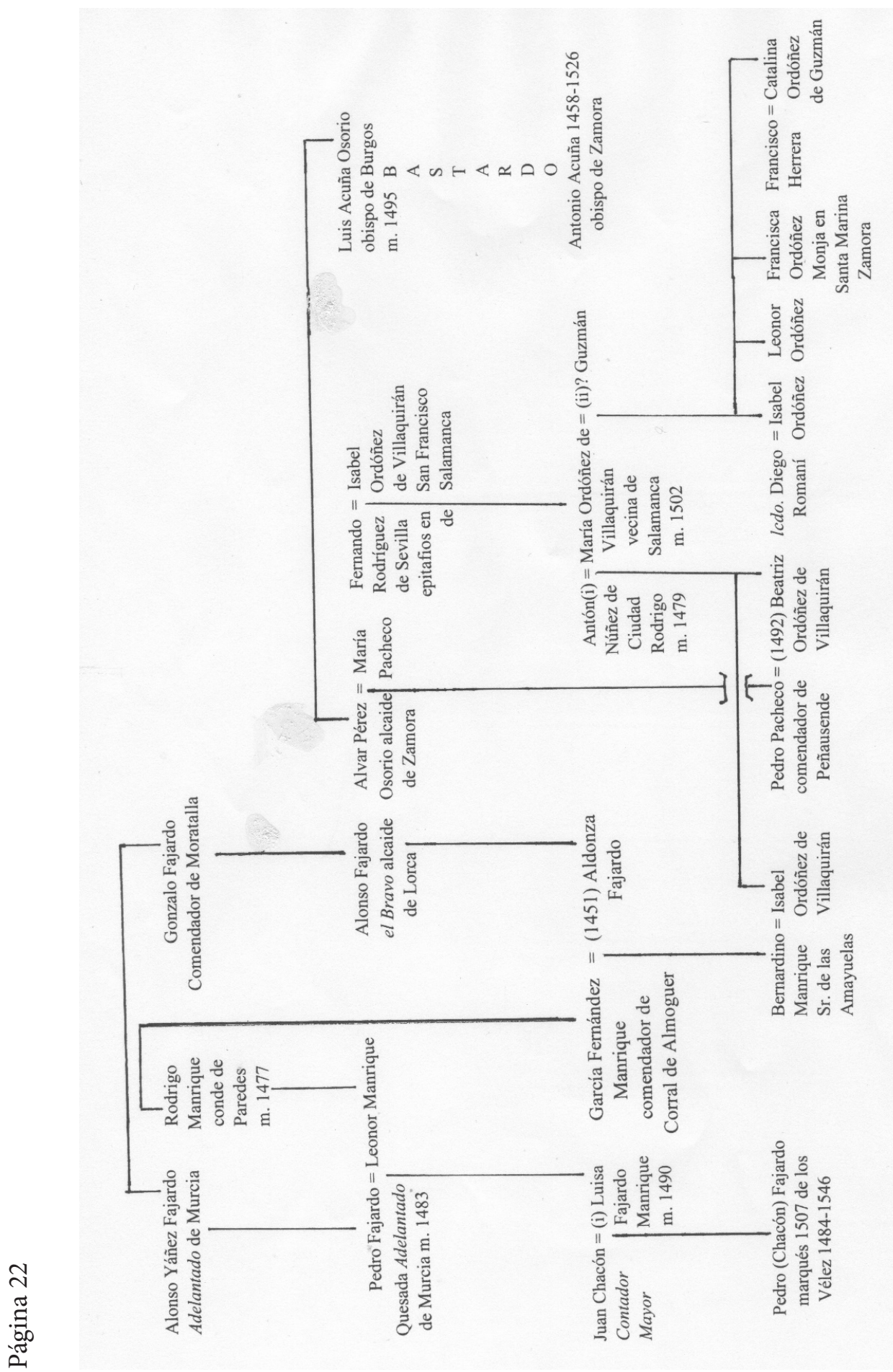


De hecho, hubo propósitos ocultos: el Deán se autonombró «prelado» de la comunidad cartagenera de los dominicos, amenazando así con socavar la autoridad del Maestro General de la Orden (Bueno, 1990, p. 22, Rubio, 2000, p. 64). El Adelantado, por su parte, ofreció como pretexto la excomunión por el obispo Juan Daza de sus escuderos (Juan Daza era pariente del futuro obispo de Zamora, que llegó a ser dos décadas después aliado del Adelantado).

Entre 1499 y 1501, es corregidor de Alcaraz el licenciado Ortuño de Aguirre. Su alcalde y alguacil es Diego de Dueñas quien, por ser vecino de Salamanca, podemos suponer otro agente del duque de Alba $^{24}$. En diciembre de 1503 el oficial ya es Gonzalo de Carvajal y Camargo, no constando la fecha de su nombramiento. Sus partidarios en el Regimiento son Gonzalo Rodríguez de Molina, Juan Sánchez del Provencio y Martín Fernández de Henarejos. Posteriormente es corregidor de Salamanca. Parece que el duque consiguió con su designación alguien favorable a sus deseos (no consta la fecha del nombramiento, pero coincide con la sucesión de Pedro Fajardo en el Adelantamiento). Carvajal tenía al menos presencia política. El 27 de abril de 1504 se le autorizó a ir a Plasencia porque su mujer Guiomar (de Silva) estaba en estado y quería dar a luz en su patria. El embarazo pudo existir de verdad ${ }^{25}$, pero el motivo más evidente tuvo que ser los disturbios que siguieron al asesinato en Plasencia de dos familiares de la facción de los Zúñiga a finales de 1503. El fiscal inculpó a varios parientes de Carvajal (Diago, 2017, p.262) ${ }^{26}$. Al corregidor se le puede identificar como sobrino del Cardenal Bernardino Carvajal y del embajador García López de Carvajal, y primo

\footnotetext{
${ }^{24}$ Interrogatorio sin fecha de una pesquisa posterior sobre el corregimiento de Ortuño de Aguirre (AMA legajo 60 exp. 8).

${ }^{25}$ AMA acta de la fecha (legajo 42 exp. 60). Parece más que dudoso que una mujer embarazada realizara un viaje de $430 \mathrm{kms}$. a caballo.

${ }^{26}$ En la década de su pontificado (1496-1506), el obispo Gutierre de Toledo, hermano del duque, había eliminado prácticamente a los Zúñiga del canonicato capitular. Al mismo tiempo fundó una nueva catedral, al estilo de los templos gemelos de Salamanca. En efecto una catedral de los duques (Martínez, 2008: p. 261). La misión de Gonzalo de Carvajal era, seguramente, conseguir la absolución de sus parientes.
} 
del padre del cronista Lorenzo Galíndez, éste un allegado del duque de $\mathrm{Alba}^{27}$.

El fallecimiento de la Reina Católica (26 de noviembre de 1504) y el advenimiento de Juana y Felipe con su correspondiente clientelismo alteraron el balance político en los órganos de la gobernación. En el caso de Alcaraz el arzobispo de Toledo, Francisco Jiménez de Cisneros, fiándose de su confianza con la difunta Reina, sometió el control de las deudas civiles en la ciudad a los fiscales de la Mitra, medida no apoyada por la nueva monarca ${ }^{28}$.

Se destaca en el concejo alcaraceño en estos años el «comendador» Diego Fernández de Córdoba ${ }^{29}$. Su orientación política, sin embargo, queda fuera de duda por la siguiente minuta de acta municipal de 30 de marzo de 1507: «rrelacion del comendador Diego de Córdoba e del maestresala que le den licencia a los de Lietor para que rieguen con el agua del alcantarilla de Bucerra $»^{30}$. El maestresala de los Reyes Católicos es Luis de Córdoba, hijo ilegítimo del primer conde de Cabra, nombrado alcaide de Requena por Felipe I en 1506 (Cooper, 2019, p. 200) ${ }^{31}$ e indudablemente un aliado del Adelantado de Murcia. El comendador es su hijo (Toral, 1994, 916).

Del siguiente corregidor, Sancho Manuel $^{32}$, no consta ni siquiera su presencia en las actas existentes del concejo alcaraceño. El apellido sugiere que es de origen murciano. Si resulta que con

\footnotetext{
${ }^{27}$ De hecho, tuvo que deber su ascensión, de hijo bastardo de un canónigo a cortesano de los Reyes, enteramente al patronazgo ducal.

${ }^{28}$ El 24 de mayo de 1505 la Reina mandó que el corregidor y otros oficiales de Alcaraz no permitieran a los fiscales del arzobispado penalizar a los civiles morosos (AMA legajo 106 exp. 64).

${ }^{29}$ En 1511 es «caballero» de la Orden de Santiago y no «comendador» (Blanco, 2004: p. 539).

${ }^{30}$ AMA legajo 42 exp. 7.

${ }^{31}$ La presencia en Alcaraz del maestresala responde seguramente a presiones políticas. Su ocupación de la alcaidía de Requena duró poco. De hecho, le representaba siempre allí un lugarteniente y, fallecido el Rey Felipe, el círculo de la Reina no tardó en intentar sustituirle con parientes del duque de Alba, aunque en el papel, su ejercicio del oficio seguía hasta 1508. Por otra parte, marzo de 1507 es el apogeo del desorden en Alcaraz, dejando al comendador falto de aliados.

${ }^{32}$ El 20 de abril de 1506 su mandato fue extendido por un año más (AMA planero 64).
} 
ese nombre es el allegado del deán de Cartagena, involucrado en los acontecimientos de 1504 en Murcia, va a ser lógicamente un contrario del Adelantado ${ }^{33}$. Casi al final de su permanencia en el cargo, la reina escribió una carta que le daría al menos un sentido de alivio:

Doña Juana por la gracia de Dios rreyna de Castilla.....a vos los concejos...de las villas e lugares del adelantamiento de Cazorla..... salud e gracia: sepades que a mi es fecha rrelacion que don $\mathrm{Rr}-$ odrigo Manrrique conde de Paredes quiere venir a la cibdad de Alcaraz e entrar e se apoderar de ella con ayuda e fabor de don Pedro Fajardo adelantado de Murcia....por ende.... vos mando que si por parte de la dicha cibdad o del corregidor de ella vos fuese pedido ayuda e fabor para la guarda e defensyon de la dicha cibdad que le deys e fagays dar e que si el dicho conde de Paredes o el dicho adelantado....quisiere entrar e se apoderar de la dicha cibdad... syn esperar otra my carta ny mandamiento....vays luego poderosamente con la gente de pie y de cavallo de todas las villas e lugares de ese adelantamiento con sus armas..... la dicha cibdad de Alcaraz e vos junteys con el conde de Tendilla my capitán general de Granada.... Que yo embyo a mandar que vaya alla en persona poderosamente....y eche fuera a qualquier grande o cavallero que en ella estuviera ....dada en la cibdad de Palencia a diez y nueve días del mes de abril año del salvador IHU XPO de myll e quinientos e siete años ${ }^{34}$.

Un mandamiento semejante fue enviado en las mismas fechas a las autoridades de Baeza ${ }^{35}$, y una carta disuasoria al Adelantado de Murcia ${ }^{36}$.

\footnotetext{
${ }^{33}$ Parece ser también el seguidor del obispo de Cartagena autorizado en 1504 a portar armas (Gomariz, 2000: doc. 597).

${ }^{34}$ AMA legajo 7 exp. 5 (citado por Pretel). Cabe suponer que había comenzado en Cazorla el mandato de García de Villarroel, sobrino del arzobispo Cisneros, como Adelantado, aunque no se le menciona por su nombre en estos documentos. En 1513 Villarroel figura como comendador santiaguista de Carrizosa (anteriormente había sido Enrique Manrique Ayala, hijo del conde de Paredes), lo cual le colocó casi en la puerta de Alcaraz.

${ }^{35}$ AMA legajo 106 exp. 58.

${ }^{36}$ AMA legajo 7 exp. 14.
} 
El conde de Tendilla no veía, aparentemente, tan grave la situación (o no quería enfrentarse con el Adelantado de Murcia) ${ }^{37}$. Ni siquiera realmente el mismo corregidor, ahora Diego Ruiz de la Mota veía grave la situación ${ }^{38}$. El nuevo titular es hermano del obispo de Palencia expulsado de la sede palentina en 1520 por el obispo de Zamora. Se le puede considerar un hombre duro, aunque no notablemente inclinado hacia el duque de Alba. Su presencia permitió al Regimiento de Alcaraz capear el temporal de la viudez de la Reina Juana hasta la vuelta a Castilla de Fernando en agosto de 1507, celebrada en Alcaraz con petardos. Es una exageración tildar a este tiempo de animadversión como un enfrentamiento con el conde de Paredes. Pleitos con el conde casi siempre había habido, e iban a continuar. El corregidor siguió el ejemplo del conde de Tendilla, al anunciar, según el acta del 26 de julio de 1507, que no tenía tiempo para intervenir en persona en las disputas con el conde de Paredes, y nombró en su lugar al bachiller Vaca.

Estas disputas giraron sobre el incumplimiento del padre del conde de Paredes de la sentencia del 12 de mayo de 1483 obligándole a observar la Ley de Toledo de 1480 con respecto al término de Alcaraz. La combatividad condal fue de poca duración: una sentencia de la Real Audiencia del 18 de julio de 1510 mandó al tercer conde a retirarse definitivamente del realengo alcaraceño ilegalmente ocupado $^{39}$. De hecho, lo que tuvo que primar fue la inseguridad que sentía con el rechazo por el Adelantado en 1507 de su primera mujer, hermana del conde, por infecundidad. El 15 de octubre se le iba a brindar al Adelantado el marquesado de los Vélez. Si el duque le

\footnotetext{
${ }^{37}$ Tampoco estaba tan distante de la situación, pues era comendador santiaguista de Socuéllamos.

${ }^{38}$ El investigador, que ha estudiado las actas del concejo de Alcaraz en esta época parece haberse equivocado en la transcripción del nombre del corregidor, poniendo «Diego Ruiz de la Mora». El escribano sí escribe la «t» y la «r» de la misma forma en numerosas ocasiones, pero Diego Ruiz aparece inequívocamente como «de la Mota», incluso en su propia firma, para que no quepa duda (Pretel, 1976, p.3).

${ }^{39}$ AMA legajo 40 exp. 46. El dictamen no hizo que el conde renunciara a Riópar.
} 
veía como impedimento a la extensión de su poder hacia el sureste, la creación del marquesado iba a subrayar esa impresión.

Por otra parte, el nuevo título iba a aumentar la ansiedad de Pedro Fajardo para tener un sucesor, y su comportamiento tuvo que ser algo imprevisible en aquellos días. Engendró a un hijo bastar$\mathrm{do}^{40}$. Eligió como segunda cónyuge, no a otra dama de la estirpe de los Manrique, (probablemente porque no había ninguna apta que estuviera disponible) sino a la hija del segundo duque de Alburquerque, nieta, por lo tanto, del duque de Alba. El enlace, en principio alarmante para el conde de Paredes, tenía sentido político, pues los dos linajes compartían un historial de pretensiones al señorío de Cartagena.

Se inquietaría asimismo el duque de Alba por otros motivos: en 1506 habían muerto su hombre de confianza en Cuenca, Pedro de Barrientos «el mozo», sin heredero y, a 28 de agosto, su hermano, el obispo de Plasencia, dejando una vacante en la sede durante más de dos años. En Alcaraz, desde julio de 1507, iba a haber un intervalo también de dos años hasta la siguiente serie de actas del concejo conservadas. El vacío coincide no solamente con la amenaza del conde de Paredes, sino con un acontecimiento a finales del año 1507, el así llamado «pleito de cucharetas», que seguramente dejó huella en el consistorio: la predicación de un franciscano en la iglesia de Santa María (Cooper, 2019, p.187) ${ }^{41}$, condenada por herética por un dominico de Murcia, desatando un conflicto que se fue intensificando.

${ }^{40}$ Lázaro de Santa Cruz. De hecho, no consta la fecha de la intimidad entre los padres, pero lógicamente ocurrió en este intervalo. Otro es Alonso Rodríguez (Roth, 2017, p. 392).

${ }^{41}$ El mecenas de los franciscanos de Alcaraz, por una supuesta afinidad con los alumbrados, era el segundo marqués de Villena. En 1507, aprovechando, se supone, el vacío en el gobierno después de la muerte de Felipe I, un tal «Portocarrero» ocupó la fortaleza de Huete. Se encargó su hermano Gutierre de Sandoval de expulsarle (Cooper, 1991: ap. doc. 407). La coyuntura identifica a «Portocarrero» como un hijo de Alejo de Sandoval y María Portocarrero, pariente esta de la primera mujer del primer marqués de Villena. «Portocarrero» se alzó en 1521 con los comuneros de la ribera del Júcar, con motivos relacionados probablemente con la herencia de los señoríos de la Ventosa y Caracena del Valle, tema inédito. Es un ejemplo más de la división vertical en la sociedad expuesta por la rebelión. 
La contienda ocurrió previsiblemente entre el fallecimiento del Maestro General de los Predicadores Vincenzo Bandelli en agosto de 1507, y el nombramiento del futuro Cardenal Cayetano a Vicario General en junio de 1508. Aunque el tema principal de la cuestión fuera en principio doctrinal, las causas tuvieron que ser políticas y exteriores a la congregación alcaraceña. De hecho, dado el patrocinio respectivo del duque y del marqués de los dominicos y de los franciscanos, es imposible que los dos grandes desconocieran la situación. El prior de San Pablo de Burgos, Pedro de Covarrubias, había advertido en el capítulo dominicano celebrado en Milán en 1505 el peligro de elementos perturbadores en los conventos (Hernández Martin, 1986, p.6). Se refería seguramente a la influencia de «la Beata de Piedrahita», que amenazaba escindir de nuevo la «Provincia de España» (de los dominicos) unida recientemente, en 1504, en el capítulo de Peñafiel bajo la bandera de la reforma ${ }^{42}$.

El dato fundamental de ella es su cercanía al duque de Alba de quien era, por el lugar de su nacimiento, su vasalla. Sobre el papel, hubiera podido ser el paladín de los predicadores, sobre todo al serle obvio al duque que el itinerario de San Vicente Ferrer en 1411 había definido exactamente el área de influencia que podría añadir al dominio de la orden dominicana si pudiera controlar la predicación ${ }^{43}$. De hecho, el duque se dio rápidamente cuenta de que promocionar la bala perdida que era «la Beata» fue un grave error de juicio.

Si el patrocinio de la orden dominicana por el duque de Alba no fue decisivo para que el marqués se comprometiera con los franciscanos, las advertencias de su corresponsal Pedro Mártir de Anglería sí lo pudieron ser. En 1512 le escribe, acerca de «la Beata de Piedrahita», tanto dominica como protegida del duque: «Audisti de muliercula quadam in oppido de Piedrahita nutrita...» (Beltrán,

\footnotetext{
${ }^{42}$ Santo Domingo de Alcaraz había aceptado la reforma de su comunidad conventual, probablemente con poco entusiasmo (Hernández Martín, 1981: p. 8).

${ }^{43}$ Murcia, Librilla, Alhama, Lorca, Mula, Alcantarilla, Molina, Cieza, Jumilla, Hellín, Tobarra, Chinchilla, Albacete, Balazote, Villaverde, Alcaraz. Las poblaciones cedidas al Príncipe en 1496 casi lo eran al duque en el mismo momento. Alcaraz figura en ambas listas.
} 
1939, p.94). La complicidad del clan Manrique/Chacón/Fajardo con la orden franciscana cubre el reino de Murcia, el obispado de Almería, la Sierra de Alcaraz y las zonas del Cerrato y Tierra de Campos (Losa, 2015, pp.32, 95, 108). La cima del involucramiento del duque de Alba con los dominicos es su subvención al convento de San Esteban de Salamanca, con su Estudio General de Teología, sede efectiva de los Predicadores en España, y la de su hijo fray Juan de Toledo quien, se supone, fue alumno del Estudio.

Este convento era también beneficiario de un hijo legítimo, hasta ahora totalmente inédito, del consuegro del duque, Juan Puertocarrero, conde de Medellín ${ }^{44}$. Se refiere a «fray Domingo de Sancti Spiritus» nacido como Alonso Puertocarrero, cuya eliminación de la carrera sucesoria en el condado dejó al desgraciado conde irreversiblemente en manos ducales (de no haber, desde luego, una puja interesante de parte del Adelantado Mayor de Murcia). No sería injusto sospechar que el duque sedujo al vástago, con una educación gratis en San Esteban, específicamente con ese fin. En el acontecimiento de Alcaraz, tanto el fraile franciscano como el predicador murciano estaban actuando fuera de sus legítimas jurisdicciones, en la frontera entre dos diócesis, lo cual indica un objetivo político ducal que pudo ser la disminución de la influencia franciscana en la zona, por una punta de lanza (fray Mateo de Valladolid) no del todo fiable pues fue repudiada luego por sus propios correligionarios.

Hacia finales de 1509 el corregidor de Alcaraz es Antonio Luzón, de afiliación desconocida ${ }^{45}$. Su «teniente» es el licenciado Briceño, cuyo apellido (abulense) le hace con bastante certeza un allegado del duque de Alba (Cooper, 1991, pp. 144, 328). Su ejercicio no carece de incidentes: el 6 de noviembre de 1509 el «procurador

\footnotetext{
${ }^{44}$ Según su testamento redactado el 4 de junio de 1514 (Gutiérrez, 1981: p.221). Una manifestación inequívoca de la penuria de los condes de Medellín es su venta en 1495 del juro del almojarifazgo de Sevilla al convento de la Madre de Dios de Toledo por 325.000 maravedís (Serrano Rodríguez 2012: p.227). Siendo este convento dominicano, cabe sospechar que el corredor del negocio fue el duque de Alba.

45 «Es uno de los corregidores más absentistas» (Pretel, 1979, p. 36). En junio de 1515 figura como gobernador del marquesado de Villena.
} 
síndico» Juan de Vandelvira hace constar que ha pedido a Briceño que no vote con los regidores. Dos días después, en clara represalia a esta reprimenda, el teniente estipula una multa para cualquier regidor que no asista a una reunión estando presente en la ciudad, o que llegue tarde (las reuniones tenían lugar a las 9 de la mañana). El día de Nochebuena, Francisco Tamajón, «fiscal» del arzobispo de Toledo (Cisneros, de nuevo) suplica avecindamiento, con su suegra. El 10 de enero de 1510, Briceño anuncia su ausencia, y nombra como suplente a Juan Cano quien también, por lo tanto, se supone, es incondicional del duque de Alba. En tres semanas ha vuelto Briceño, pero dura poco en el oficio. El 27 de agosto el comendador Diego Fernández de Córdoba comenta que su hijo el bachiller Pedro de Córdoba es «letrado» del consistorio y va a casarse. Propone por suplente al licenciado Blázquez, con un ducado a pagar al bachiller Arenas. Estos presumiblemente son partidarios del marqués de los Vélez.

El poderío oculto del marqués, tal vez un presagio del periplo de Lucas de Tauste más de una década en adelante, se descubre en el caso siguiente:

[...] a cinco dyas de hebrero de quinientos e honse años...(los alcaldes de la Hermandad de Ciudad Real)) mandaron dar a Diego de Vyllaquiran alguasyl de la dicha hermandad myll e quinientos maravedís e a vn peon que llevo seyscientos e ochenta maravedís de veynte dyas que fueron a la cibdad de Murcia a prender a Martyn fijo de Pedro Alonso por querella que de el fue dada por quanto el en traycion a la Rreina nuestra señora que fue en la muerte del alcayde del convento de Calatrava para se alçar con la dicha fortaleza y porque no auya podido saber donde estava fasta agora que se supo que estaua en la cibdad de Murcia e traya abito de frayle por se librar de la muerte. El dicho alguasyl fue y estuvo los dichos veinte días y hallolo en la cibdad de Murcia y no lo pudo prender por que se metyo en el monesteryo de Sant Francisco y dio de comer los dichos veynte dyas al dicho peon e a vn espya que llevo ${ }^{46}$.

\footnotetext{
${ }^{46}$ Archivo Histórico Nacional: Diversos - Hermandades leg. 56/15 (signatura facilitada por Gómez Vozmediano, 1996, p. 143). Se trata de la Hermandad Vieja de Ciudad Real.
} 
De ninguna manera hubiera podido eludir la justicia el delincuente sin el apoyo tanto del marqués como del conde de Paredes. En esta época hay otro espacio de 3 años en las actas del concejo de Alcaraz, hasta el corregimiento de una figura ya conocida, el comendador Gamarra, ya instalado en octubre de 1513. Teniendo en cuenta el contexto, hay que pensar que su nombramiento había sido hecho precisamente por su experiencia en controlar a los Chacón/ Manrique. No es aventurado suponerle de hecho partidario del marqués de los Vélez, pues el 3 de febrero de 1505, atendido por varios de sus criados, había presidido la confirmación del entonces Adelantado como comendador de Caravaca (Pozo, 2011, p.49).

De momento lo único que tiene que supervisar Gamarra son las anomalías en el comportamiento del comendador Diego Fernández de Córdoba. Según acta del 29 de diciembre de 1513, el bachiller Pedro de Córdoba se había casado con una tal Ana Herrándes. Uno se pregunta si sigue siendo menor de edad, pues el mismo día de la Nochebuena pide un permiso para cazar perdices, para celebrar el desposorio. Igual de curioso es que el comendador y Juan de Luna den fianzas para que el novio se avecinde en Alcaraz ( ¡habiendo sido letrado del concejo desde 1510 !) ${ }^{47}$.

Frente a lo que parecen irregularidades ${ }^{48}$ en los nombramientos a los puestos del consistorio, el corregidor elige retirarse a su encomienda valenciana (14 de febrero de 1514), aunque hasta el día 28 no está demostrado que marchara. El 8 de abril vuelve a asistir al ayuntamiento. No consta la causa de su ausencia pero, dado el poco convincente pretexto del corregidor Carvajal, se puede sospechar una razón que no quería declarar. En agosto de 1501, la Corona le había enviado al inhóspito pie de la montaña alpujarreña para intervenir en la cobranza por el marqués del Cenete de un im-

\footnotetext{
${ }^{47}$ Acta de 4 de abril de 1514.

${ }^{48}$ Estas continúan: El 24 de diciembre de 1519 varios regidores hacen constar que los descontentos exoficiales Luis Pinilla, Alonso Arcayos y Diego Bonjorne han denunciado a la ciudad en la Real Audiencia sobre los alferazgo, escribanía, y obrería. Por desafectos que fueran los interesados, su desagrado no fue tanto que les convirtiera en comuneros.
} 
puesto no autorizado a sus vasallos moriscos en la Calahorra y sus pedanías $^{49}$. En 1514 ya estaba fallando la iniciativa del marqués en la Calahorra, y en el plazo de dos años abandonaría para siempre su adorado castillo para pasar el resto de su vida en Valencia. Es posible que su amargura le llevara a buscar contra Sagra y Cenete represalias por la actuación de Gamarra, aunque fueran tardías, desde su señorío de Alcosser de Planes (Comtat), situado a una distancia de $20 \mathrm{kms}$.

Las irregularidades, y la distribución de los regimientos por cinco colaciones, se prestaría a la formación de facciones, pero no ocurre de una forma tan precisa. Simplemente indicios de toma de partido: del conde de Paredes, se puede decir, son los Córdoba, Pedro Hernández del Busto, Juan de Luna, el licenciado Blázquez, el bachiller Arenas. Juan de Claramonte, alcalde de la Hermandad en 1518, es pariente de Gil Sánchez Soriano. Diego Vaca parece ser partidario del duque de Alba. La prueba más resolutoria es su patrocinio del convento dominicano de Alcaraz (Ayllón, 2015, p.197) ${ }^{50}$. Al mismo tiempo, iba a depender del favor de algún potentado, al tener ascendencia judía, nacimiento ilegítimo y una falsificada genealogía petrista. En el edilazgo, es el único culpable de una atrocidad. El 5 de julio de 1514, el contino Juan de Bustamante le denuncia por haber fortificado una casa adosada a la muralla y asesinado a su hermano Bernardino de Montiel. Diego Vaca fue condenado a muerte por el licenciado Montalvo, pero estaba todavía en libertad en enero del siguiente año (Cooper, 1991, ap. doc. 383). ¿Protegido por el duque de Alba? Protegido por alguien.

No se sabe si el comendador Gamarra consiguió controlar la situación, pues trascurre otro intervalo de tres años sin vestigios de las actas municipales. Cuando vuelve a comenzar la serie en octubre

\footnotetext{
${ }^{49}$ AGC Sello agosto de 1501 fol. 90.

${ }^{50}$ No he podido identificar sus enlaces matrimoniales. Una de sus esposas se llamaba Isabel Manrique. Su hermana, cuyo nombre se desconoce, se casó con un primo de la primera duquesa de Alba, un hijo del conde de Tendilla (RAH Salazar M1 fol. 138).
} 
de 1517, el corregidor es Juan de Villarroel, un pariente de Cisneros, suponiendo que sea el jurado de Cazorla y después alcalde mayor Villanueva del Arzobispo, de ese nombre, instalado por García de Villarroel (García Guzmán, 206, p.104 ${ }^{51}$ ). Fuerza la credulidad del lector tener que imaginar que las actas de más de tres años seguidos han desaparecido por puro accidente, pues cubren el fallecimiento del Rey Católico el 23 de enero de 1516 con repercusiones por todo el reino que hubieron de tener alguna manifestación en Alcaraz (Prieto, 1975, docs. 2, 40, 56). En Huete el tal «Puertocarrero» aprovecha el interregnum para levantar una casa fuerte que la Corona se apresura a proscribir (Cooper, 1991, ap. doc. 407). Surgieron bandos en el convento de la Merced en Murcia, en Burgos entre el condestable Íñigo Fernández de Velasco y el obispo Juan Rodríguez Fonseca, en un beneficio del obispado de Oviedo, en Cadiz y Sevilla entre el duque de Arcos y el de Medina Sidonia, entre el obispo de Segorbe y la orden de Santiago, en Toro entre Juan de Ulloa y el mismo obispo de Burgos etc. (Cooper, 1991, ap. docs. 405, 406, 408-412, 413-419).

De más trascendencia para Alcaraz iba a ser el golpe del conde de Paredes quien, el 15 de febrero, expulsó de Huéscar a la administración del duque de Alba, para favorecer a los partidarios del hijo del condestable de Navarra. Es evidente el apoyo del marqués de los Vélez (Cooper, 2019, p.46). Se produjo un bloqueo que duraría hasta 1522, nutrido por numerosas huestes procedentes de los adelantamientos de Cazorla y Murcia, aunque la constancia del mismo conde pudo flaquear posteriormente: en enero-febrero de 1521 las fuerzas comuneras del obispo de Zamora asolaron la sede condal de Paredes de Nava (Pérez, 1999, p. 276) ${ }^{52}$. Resolutoria en las lealtades del círculo del marqués de los Vélez es la complicidad con el rescate del obispo de Zamora, no visible antes de mediados

\footnotetext{
${ }^{51}$ En la iglesia de Santiago, de Vélez Blanco, existe la capilla de los Villarroel.

${ }^{52}$ En las explicaciones de este acontecimiento, queda una anomalía por explicar. Fuentes de Nava, que se supone formaba parte del alfoz de Paredes, fue considerado tan comunero que la Corona le escarmentó posteriormente con rigor.
} 
del verano de $1522^{53}$

Unos meses después sustituye a Villarroel en Alcaraz García Manrique. Por eliminación de otras posibilidades este parece ser García Fernández Manrique y Villaquirán, señor de las Amayuelas y pariente del licenciado Romaní. Expresa lo que parece ser su neutralidad con su frecuente ausencia. Quedando el poder ejecutivo alcaraceño en manos del alcalde mayor, el bachiller Diego de Sacedón, otros oficiales, en particular el procurador síndico, toman la iniciativa sobre asuntos que normalmente serían responsabilidad del corregimiento. Caracterizan la época constantes alteraciones, sin que se llegue a la violencia. En una de ellas, según acta del 15 de abril de 1518 el licenciado Montiel se niega a representar la ciudad por una dieta de 100 maravedis en un pleito a oír en Medina del Campo con la frecuentemente litigiosa Villanueva de la Fuente. Se supone que es pariente del difunto Bernardino, y es más, que el licenciado Montiel es el teniente con mismo nombre de Rodrigo de Cárdenas, nombrado corregidor de Cuenca en noviembre de 1519, presumiblemente un oficio mejor remunerado.

En cuanto van llegando las tensiones en el resto de Castilla a su apogeo, en marzo de 1520 el corregidor simplemente ha desaparecido, y el procurador síndico propone ausentarse de igual manera. Los regidores reconocen el estado de crisis y ponen patrullas en la ronda. Después de una plaga de langosta amenaza una carencia de pan. El corregidor no vuelve y el 27 de marzo de 1520 le sustituye Francisco Mendoza ${ }^{54}$. El procurador síndico Sancho García propone

\footnotetext{
${ }^{53}$ Corrió ligeramente mejor suerte el Mariscal Gómez de Benavides, casado con la tía del $3^{\text {er }}$ conde de Paredes, hermanastra a la vez del marqués de los Vélez y evidentemente su aliado. Los rebeldes al mando del obispo Acuña llegaron a su señorío de Frómista (Tierra de Campos) el día 1 de febrero de 1521. Impusieron una multa ruinosa para no asolar al pueblo entero (Revuelta, 1987, p.53). Como comenta este autor, no fue ningún acto de igualitarismo, sino la simple sustitución de un señorío por otro. El aplacamiento no iba a ser óbice para que en abril el mariscal presenciara los acontecimientos ocurridos en el campo de Villalar y la ejecución de Padilla.

${ }^{54}$ No hemos podido averiguar exactamente quién es. Puede ser el Francisco Hurtado Mendoza nombrado corregidor de Requena el 3 de marzo de 1522.
} 
alejarse a una localidad que evita identificar. Los regidores le informan rotundamente que, si quiere estar fuera, puede acompañar al regidor Francisco Robres para llevar un mensaje congratulatorio al cardenal Adriano en la Corte. Robres al menos llega y su recado es agradecido por el mismo Emperador. El 5 de julio el nuevo corregidor avisa a los regidores de que tiene derecho a tres meses de ausencia del corregimiento sin detrimento de su salario y se dispone a marcharse inmediatamente. Este conflicto de responsabilidades de los oficiales es exactamente lo que está encontrando el licenciado Montiel en Cuenca: pero, al final, la conciencia le pica a Mendoza y vuelve el 9 de septiembre, prescindiendo generosamente de un mes de sus vacaciones.

Son evidentes las divisiones en Alcaraz. Por una parte, hay expresiones de patriotismo hasta bajo el corregidor Manrique: el 4 de octubre de 1518 los regidores proclaman «Alcaraz llave de toda España cabeza de Extremadura». Entretanto ocurrió un incidente que puso a prueba la solidaridad de los ediles: los repartidores de la alcabala del año 1518, el bachiller Dos Barrios, Pedro Morcillo y Gil de Alcaraz, demandaron su contribución al bachiller Guerrero quien era, o pretendía ser, estudiante en la universidad de Salamanca. El maestrescuela juez conservador de la universidad declaró la inmunidad fiscal del bachiller en una carta de emplazamiento a los regidores, quienes nombraron a Diego Campillo para ir a Salamanca a defenderles ${ }^{55}$. El maestrescuela del momento habría sido o Juan Hurtado de Mendoza, cuyo ascenso se debía en gran parte al patrocinio del duque de Alba, o su tío ${ }^{56}$.

Por trivial que pudo parecer este asunto, tuvo un antecedente que le hizo cobrar importancia: el mismo príncipe Don Juan en su capacidad de señor de Salamanca, había mandado al maestrescuela que no permitiera la presencia en el Studium de religiosos no suje-

\footnotetext{
${ }^{55}$ Acta de la reunión del Regimiento de 10 de mayo de 1519.

${ }^{56}$ Como Juan Hurtado se había encontrado en el séquito del Príncipe para concertar su enlace con Margarita de Austria, se puede deducir que, a partir de ese momento, era incondicional del duque, y lo es claramente todavía en 1521 (Beltrán, 1939, cap. 7).
} 
tos al prior de San Esteban. Es legítimo especular si el comendador de la Magdalena fue también portador de este mandamiento, repetido por los mismos Reyes en el año del envío del Príncipe a Alcaraz (Beltrán, 1939, p. 58-59) ${ }^{57}$. La amenaza del maestrescuela no hace que el concejo vacile en su lealtad: el acta del 28 de febrero de 1520 se refiere a «sus cesáreas majestades».

De hecho, las abundantes declaraciones de lealtad a la Corona hacen que uno se pregunte quíen lo dudaba, y con qué motivo. Después de la derrota de los rebeldes, es decir en 1521 o 1522, tres regidores alcaraceños, Francisco Guerrero, alcaide de Beas de Segura $^{58}$, el licenciado Pedro de Avilés, procurador universal de Alcaraz y Juan Fernández procurador síndico, compusieron lo que parece ser un borrador de petición al Emperador que le recuerda los servicios prestados por la ciudad a la Corona, y que incluye esta demanda:

Y otrosy dezimos que antiguamente en tiempo de los señores rreyes vuestros progenitores la dicha cibdad de Alcaraz tuvo voz e boto en Cortes y quando se hasia llamamiento para cortes hera llamada para que enbiara sus procuradores a ellas como las otras cibdades de estos rreynos que tienen votos segund parece por estas cartas de llamamientos de los señores rrey don Juan e rrey don Enrrique e porque a cavsa de las alteraciones pasadas la dicha cibdad de Alcaraz syguio el seruicio de vuestra magestad y no quiso seguir el proposito y dañada yntincion de la dicha cibdad de Toledo fueron por ella amenazados muchas vezes y no es razon que estén debaxo de su voto mas rrazonable cosa es que tenga la dicha cibdad de Alcaraz voto con que syrua a vuestra alteza como siempre fizieron por ende suplicamos a vuestra alteza mande dar su

\footnotetext{
${ }^{57}$ No consta la fecha. La medida fue tan severa que no quiso cumplirlo el mismo prior de San Esteban y se llegó posteriormente a un compromiso. Es evidente que en 1519 no se había disminuido la autoridad del maestrescuela.

${ }^{58}$ Orden de Santiago. Adquiere la encomienda el 24 de marzo de 1491 Fadrique Enríquez de Ribera el futuro marqués de Tarifa, primo del segundo duque de Alba (Valencia, 1999, p. 464). El nombramiento coincide con el enlace del conde de Feria con la hermana del duque. Sin embargo, en 1516 figura como comendador el hermano del duque, Hernando Toledo, trece de la Orden de Santiago (Cooper, 1991, p. 275, nota 64). De todas maneras, es indiscutible el mando del duque en esta encomienda.
} 
carta e prouisyon rreal para que la dicha cibdad de Alcaraz tenga voto en cortes... como se vso e acostumbro antiguamente... ${ }^{59}$

Está claro qué es lo que determina la política seguida por los alcaraceños. De pensar que su solicitud sería rechazada por los gobernadores, se habrían unido abiertamente a la causa popular. La intervención del alcaide de Beas en el envío al Emperador sugiere que estaban guiados por el duque de Alba, que tenía sus propios motivos para influir. El 9 de septiembre de 1520 el licenciado Cano, Luis de Córdoba, Juan Hernández Salinero y el mismo Francisco de Robres asistieron a una Junta con el común de Montiel. Titubeaba en ese momento la lealtad de los alcaraceños. Se esperaba como mínimo diversidad de opiniones: el día 18 del mismo mes ${ }^{60}$ se mandó al herrero mantener abierta la forja 24 horas, y no salir de la ciudad. Dos días después los regidores consintieron en mandar al Comendador Arroyo a la corte imperial, tal vez con este mismo borrador.

Dado el descontento registrado es lícito especular por qué la comunidad de Alcaraz no hizo causa común con la de Chinchilla. Un detallado análisis de los tejemanejes de la oligarquía de Chinchilla en este tiempo ofrece amplio material para hacer la comparación. La representación de Chinchilla en Cortes correspondía a Murcia, la que, como Toledo con Alcaraz, no prestaba mucha atención a sus requerimientos. El radicalismo se manifestó en un deseo de separarse del marquesado, hecho público en 1516 cuando la ciudad, acompañada de Albacete, se negó a asistir a la reunión tradicional celebrada en Corral Rubio para acordar medidas de seguridad después de la

${ }^{59}$ AMA legajo 7 exp. 4. El recopilador de la documentación le pone fecha de 1517(?). Claramente no lo es, pues ha de ser de la siguiente década. Pese a la falta de fecha o formato oficial, parece que fue recibido por los gobernadores. Es notable que, a principios del siglo XVI, Alcaraz había logrado trasladar la administración de la Inquisición en su territorio de Toledo a Jaén, y se había resistido a incorporarse a la Hermandad de Toledo/Talavera/Ciudad Real (Domínguez Nafría, 1997, pp. 96, 101).

${ }^{60}$ Pretel $(1977$, p. 36) cita una carta de protesta del conde de Paredes redactada en las actas de la misma fecha, pero no hemos podido encontrarla. No quiere decir que no exista - puede constar en otro sitio. 
muerte del Rey Católico (Pretel, 1989, p. 231). De la misma forma que los alcaraceños, Chinchilla intentaba acercarse directamente al César, en contra de las órdenes del gobernador del marquesado Diego de Vargas. No consta en qué terminó la disensión: como Alcaraz, Chinchilla no conserva la documentación municipal generada de 1520 a 1521.

Aun faltando este fondo de información es evidente que las circunstancias de los dos municipios son notablemente distintas. El 10 de mayo de 1520 el alcaide de Chinchilla Gabriel de Guzmán informa al Regimiento que el síndico procurador de la comunidad ahora es él. Nombra a un pregonero con atributos de verdugo. En efecto ha usurpado la autoridad del gobernador del marquesado. El parecido no es con ninguna gestión en Alcaraz, sino con la acción de Juan de Comas en Requena. Chinchilla sufría graves problemas económicos y demográficos en el periodo post-Pacheco, aunque permanecían en la ciudad partidarios del segundo marqués de Villena. La ambivalente situación jurídica de la ciudad, dentro de un marquesado que había dejado de ser señorial, es probablemente lo que causaba la fragmentación de grupos políticos: «Cada grupo de personas influyentes procuraba contentar a su clientela, así las tensiones verticales se disolvían en un juego de fuerzas mucho más horizontal...» (Pretel, 1989, p. 202) ${ }^{61}$.

\footnotetext{
${ }^{61}$ La evolución fiscal de Chinchilla seguía una pauta que, según se sepa, no ocurrió en Alcaraz:
}

Durante los últimos años del siglo XV y primeros del XVI floreció en las tierras del marquesado de Villena, por entonces recientemente reintegrado a la Corona, una lucrativa actividad económica, el arrendamiento de rentas, gestionado por un importante grupo de hombres de negocios. En algunos casos esos recaudadores de impuestos eran originarios del lugar y llegaron a este mundo del dinero procedentes del sector mercantil. Pero, en su mayor parte los arrendatarios fueron miembros de importantes compañías financieras, cada vez más especializadas y radicadas fuera del señorío, en ocasiones en zonas muy distantes (González Arce, 2016, p. 6).

El domicilio principal «a distancia» en esta época parece ser Sevilla. 
Las últimas actas concejiles del año 1520 conservadas en Alcaraz tienen una letra clara y ordenada, compuesta sin prisa y que no presagia ninguna revolución apocalíptica. Pero tal como encontramos en la mayoría de los centros en donde hubo quiebra total del orden público, e igual que en anteriores momentos de crisis política en el reino, ha desaparecido allí la documentación que existía generada por los organismos locales durante los días más álgidos de la rebelión. Consta después que Alcaraz envió copiosas mesnadas a la jornada del Romeral, pero en Alcaraz las actas municipales no vuelven a conservarse hasta la del 6 de octubre de 1523.

Actividad consistorial en el entreacto sí había habido: el 19 de diciembre de 1522 Francisco Guerrero, llamándose mensajero de la ciudad, se responsabilizó de escribir al Emperador reiterando la lealtad de la ciudad, la malevolencia de los toledanos y las amenazas esgrimidas por estos ${ }^{62}$. Se vanagloriaba de que en 1475 Alcaraz había expulsado del alcázar al alcaide puesto por el marqués de Villena, Martín de Guzmán. Omite mencionar que dicho Guzmán fue el autor de una ordenanza de 1471 sobre la conservación del bosque, incorporada en la recopilación de las ordenanzas redactada en plena época de los disturbios en $1521^{63}$.

El escenario, de contienda entre dos entidades paritarias, no es el que pinta el distinguido historiador francés sobre el campo de Villalar:

Así acabó la rebelión de las Comunidades. Los nombres más ilustres de la nobleza castellana se hallaban presentes en aquella ocasión: el Almirante de Castilla, el Condestable, el duque de Medinaceli, los condes de Haro, Benavente, Alba de Liste, Castrojeriz, Osorno, Miranda, Cifuentes, los marqueses de Astorga y de Denia.... La presencia de todos estos aristócratas sobre el campo de Villalar no deja lugar a dudas sobre el significado del acontecimiento. El gran triunfador de aquel 23 de abril de 1521 no era tanto el poder real como la aristocracia, amenazada en su función política

\footnotetext{
${ }^{62}$ Archivo Municipal de Alcaraz Legajo 7 exp 3.

${ }^{63}$ Y de nuevo en 1538 (García Díaz, 1987: ap. 4).
} 
y desafiada como potencia económica y social (Pérez, 1999, pp. 314-315).

Sí que había un desfile de los grandes. Pero no estaban ni el duque de Alba, ni el marqués de los Vélez, ni tampoco el conde de Paredes. Su lucha se llevaba a cabo en otros parajes, y no terminó en el campo de Villalar. Como bien pronuncia el mismo autor, es importante no simplificar en exceso.

En las primeras reuniones de los ediles alcaraceños registradas después del intervalo de tres años, un cambio notable es el predominio en las reuniones de Luis de Córdoba, que parece autonombrarse emisario al Consejo Real, y de su nieto Pedro, ya procurador universal, que se tilda de «noble señor», seguramente una exageración. Las reuniones facilitan tan solo una somera idea de lo que pudo ocurrir en Alcaraz a consecuencia de la rebelión, específicamente por la petición al corregidor para que obtenga la asistencia de un pesquisidor para averiguar «los daños que ha rescebido esta cibdad en las talas e cortas que azen en ellos» (los términos de Alcaraz) «los de fuera de la juredicion». Estos estragos habían sido una constante en la historia de Alcaraz, pero esta ocasión es la primera en la que habían adquirido suficiente gravedad para que el Regimiento pida la intervención de un pesquisidor.

En Murcia triunfó el duque Alba frente al marqués de los Vélez (Cooper, 2019, pp. 66, 69). A la Mancha llegaría en menos de una década otro tipo de pesquisidor. En 1530 actúa en las Cinco Villas del Campo de Calatrava el Inquisidor Juan Yáñez (Dadson, 2017, pp. $39,105,108)^{64}$. El marqués de los Vélez comentó de él en 1526, «el

\footnotetext{
${ }^{64}$ Yáñez había pasado previamente por Ocaña, la encomienda santiaguista más poblada de la Ribera del Tajo. El autor comenta (pág. 257): «la Inquisición siempre era una presencia o sombra amenazante para los moriscos del Campo de Calatrava, por muchas familias que tuviesen en sus filas». Puede ser pura coincidencia (entre las otras muchas que he identificado), que Gaspar Rótulo, el empresario milanés a quien el marqués de los Vélez contrató la producción de Mazarrón durante 9 años en 1532, era vecino de Almagro, en pleno Campo de Calatrava (Franco, 1980: 256). El segundo duque de Alba había fallecido un año antes. El contrato fue rescindido antes de su vencimiento.
} 
Inquisidor de Murcia Juan Yañez es de Medelyn natural, y por ello vasallo del nieto del duque de Alba que es conde de ally» (Cooper, 1991, ap. doc. 276) ${ }^{65}$. El año 1526 es cuando Yáñez es trasladado de Jaén (y se supone de Murcia) al arzobispado de Granada y, a corto plazo al arzobispado de Toledo, con el cometido de aplicar con la mayor severidad los castigos de la Inquisición a los moriscos remisos en abrazar la Cristiandad con convincente piedad. Para un señor con muchos vasallos moriscos, como era el marqués de los Vélez, tener un adversario que controlaba la Inquisición fue la mayor desventaja posible $^{66}$. Lo mismo se puede decir para los calatravos de las Cinco Villas. Parece que la compenetración con la Inquisición por el duque de Alba en la persona de Juan Yáñez es comparable a su dominio de los Predicadores o de la corte del Príncipe.

${ }^{65}$ Otras fuentes pretenden que Yáñez nació en Casas de Millán (Riberos de Tajo) en el obispado de Plasencia, igualmente extremeño y fácilmente dominado por el duque de Alba. Al final de su vida fue nombrado obispo de Calahorra. Murió en 1544 a los 70 años. Su secretario del secreto, como Inquisidor en Granada, es el licenciado Guerrero, pudiendo ser el mismo que el bachiller Guerrero, del pleito de 1518 del concejo de Alcaraz, o incluso el bachiller Juan Martínez Guerrero, emisario del duque de Alba a Alcaraz en 1497. 0 ninguno de ellos.

${ }^{66}$ Hasta 1525 el marqués había tenido su propio Inquisidor de plantilla, Juan Ruiz de Salvatierra, enviado entonces a servir en Cuenca para eliminarle por el arzobispo de Sevilla, cuyos tribunales el marqués consideraba dominados por allegados del duque de Alba. El arzobispo entonces era Alonso Manrique, en el papel partidario del marqués, siendo hermano de su abuela, pero manipulado por sus oficiales, motivo probable de la opinión negativa del marqués. Siendo Salvatierra también provisor del obispado de Cartagena, podía cumplir los fines del marqués en esa capacidad, por ejemplo, en Chinchilla (Ayllón, 2016, pp. 39-54). 


\section{REFERENCIAS BIBLIOGRÁFICAS}

ÁLVAREZ GARCÍA, C (1986). La Revolución de las Comunidades de Castilla en Medina del Campo. En. E. Lorenzo Sanz (coord.), Historia de Medina del Campo y su tierra. Vol. 1, 471-576. Medina del Campo - Ayuntamiento.

AYLLÓN GUTIÉRREZ, C. (2008). Sobre las parroquias de Alcaraz a finales de la Edad Media. Cultural Albacete (12-13) 27-33.

AYLLÓN GUTIÉRREZ, C. (2009). Los Soriano: Otro Linaje Eclesiástico en el Cabildo de Cartagena. Murgetana (120) 95-110.

AYLLÓN GUTIÉRREZ, C. (2015). Pedro Vaca, Héroe Alcaraceño en la Batalla de Toro y Agente de los Reyes Católicos. Al-Basit (60) pp. 171-212.

AYLLÓN GUTIÉRREZ, C. (2016). Bernardo de Andújar, obispo de Tagaste. Murgetana (135) pp. 39-54.

BELTRÁN DE HEREDIA, V. (1939). Historia de la Reforma de la Provincia de España Institutum Historicum FF. Praedicatorum BLANCO RODRÍGUEZ, D (2004). Santiago y Calatrava en Transición. Historia, Instituciones, Documentos (31) 511-542.

BOASE, R. (2017). Secrets of Pinar's Game. Brill.

BUENO ESPINAR, A (1990). El Monasterio de Santa Ana: las Monjas Dominicas de Murcia. Caja Murcia.

CAMPO DEL POZO, F. (2005). Voto de Medina del Campo por la Purísima Concepción de María. En F.J. Campos y Fernández de Sevilla, coord., La Inmaculada Concepción en España. San Lorenzo del Escorial, R.C.U. Escorial-Mํㅡ Cristina, vol. 1, 385408.

CARVAJAL DE LA VEGA, D. et al. (2015). Mercaderes y Cambiadores en los protocolos notariales de la provincia de Valladolid. Valladolid: Universidad de Valladolid.

COOPER, E. (1991). Castillos Señoriales en la Corona de Castilla. Junta de Castilla-León.

COOPER, E. (2019). Siete Episodios de la Rebelión de las Comunidades de Castilla (1520-1521). Íberoamericana Libros. 
DADSON, T. J. (2017). Tolerancia y Convivencia. Cátedra

DIAGO HERNANDO, M (2017). Violencia en las Actuaciones Políticas del Clero Catedralicio en Plasencia a Fines del Siglo XV y Comienzos del XVI. Espacio, Tiempo y Forma (30) 247-272. DOMÍNGUEZ NAFRÍA. J.C. (1997). Derecho Real y Autonomía Concejil. Murgetana (96) pp. 64-102.

FERNÁNDEZ MARTÍN, L. (1993). El incendio de Medina del Campo, 21-VIII-1520, un testimonio inédito. Investigaciones Históricas (13) 95-106.

FRANCO SILVA, A. (1980). El Alumbre Murciano. Miscelánea Murciana Medieval (6) 237-272.

GARCÍA DÍAZ, Í (1987). Agricultura, Ganadería y Bosque. Albacete: Instituto de Estudios Albacetenses

GARCÍA DÍAZ, Í (1989). Mayorazgo y Vinculación de la Propiedad Señorial en Murcia a Fines de la Edad Media. Miscelánea Medieval Murciana (15), 139-184.

GARCÍA GUZMÁN, M. M. (2006): El Señorío de Cazorla en la baja Edad Media. EPCCM

GOMARIZ MARÍN, A. (2000). Documentos de los Reyes Católicos 1492-1504. Real Academia de Alfonso X.

GÓMEZ VOZMEDIANO, M. F. (1996). La Revuelta de las Comunidades en La Mancha (1519-1531). Chronica Nova (23) 135-169.

GONZÁLEZ ARCE, J. D. (2016). Arrendamiento de Rentas Reales y Negocio Fiscal en el Señorío de Villena. Al-Basit (61) pp. 5-53 GUTIÉRREZ, A. (1981). El Becerro de 1513 del convento de San Esteban de Salamanca. Archivo Dominicano (2) 141-234).

HERNÁNDEZ MARTÍN, R, (1981): Actas de la Congregación de la Reforma. Archivo Dominicano (2) 5-113

HERNÁNDEZ MARTÍN, R (1986). Actas de los Capítulos provinciales de la Provincia de España del siglo XVI. Archivo Dominicano (7) 5-47.

IGUAL LUIS, D. (2014). La producción y el Comercio del Alumbre en los Reinos Hispánicos del siglo XV. Mélanges de l'École Française de Rome - Moyen Age (126-1) Roma École Française de Rome. 
LOSA SERRANO, P (2015). De comendadores a maestre de la Orden de Santiago: el señorío manriqueño de la sierra de Alcaraz. Silex

MARTÍNEZ. R. L. (2008). From sword to seal: the ascent of the Carvajal family in Spain (1391-1516). Universidad de Texas.

MESEGUER FERNÁNDEZ, J. (1972). Alejandro VI y el eremitorio de San Ginés de la Jara, 1494. Archivo Íbero-Americano (128) 524-526.

MONTERO TEJADA, R. M. (1996). Nobleza y Sociedad en Castilla: el linaje Manrique. Caja de Madrid.

MORALES MUÑOZ, D. C. (1987). Un documento de la Princesa Isabel de Castilla, Señora de Alcaraz. Al-Basit (21) 83-87.

PEÑA BARROSO, E. DE LA (2017). El Abad de Medina y la «comunidad» de Medina del Campo. En I. Szászdi León-Borja (coord.), Iglesia, Eclesiásticos y la Revolución Comunera, 353-380. Centro de Estudios del Camino de Santiago.

PEREZ, J. (1999). La Revolución de las Comunidades de Castilla. (versión en castellano, Siglo Veintiuno.

POZO MARTÍNEZ, I. (2011). Comendadores y Alcaides de Caravaca durante la Edad Media. Murgetana (125) 9-84.

PRETEL MARÍN, A (1976). Noticias sobre el castillo de Riópar en la Edad Media. Al-Basit (2), 7-24.

PRETEL MARÍN, A (1976). El frustrado ataque del Conde de Paredes contra la ciudad de Alcaraz, a la muerte de Felipe el Hermoso. Al-Basit (3) 27-35.

PRETEL MARÍN, A (1977). La intervención de la ciudad de Alcaraz en la Guerra de las Comunidades. Al-Basit (4) 33-41.

PRETEL MARÍN, A (1979). La integración de un municipio medieval en el estado autoritario de los Reyes Católicos. Instituto de Estudios Albacetenses

PRETEL MARÍN, A (1989): La «comunidad y república» de Chinchilla (1488-1520). Evolución de un modelo de organización de la oposición popular al poder Patricio. Instituto de Estudios Albacetenses. 
PRIETO CANTERO, A. (1975). Documentos Inéditos de la época del Cardenal fray Francisco Jiménez de Cisneros. Anales Toledanos (7-8) 5-130

REVUELTA GONZÁLEZ, M. (1987). La villa de Frómista en dos momentos de su historia. Publicaciones de la Institución Tello Téllez de Meneses (56) 31-58.

RODRÍGUEZ LLOPIS, M. \& GARCÍA DÍAZ, I. (1994). Iglesia y Sociedad Feudal. Universidad (Murcia), Secretariado de Publicaciones. RODRÍGUEZ SÁNCHEZ, Á. (2001). La Muerte del Príncipe de Asturias, Señor de Salamanca. Revista de Estudios Extremeños (57) 23-48.

ROTH, D. (2017). La Construcción de las Iglesias de Vélez Blanco y el Traslado de los Supuestos Restos Mortales del Primer y Segundo Marqués de los Vélez. En J. P. Díaz López (coord.): La Historia de Almería y sus Historiadores 377-406. Instituto de Estudios Almerienses.

RUBIO GARCÍA, L. \& RUBIO HERNANSÁEZ, L. (2000). La Mujer Murciana en la Baja Edad Media. Murcia, Universidad.

SÁNCHEZ FERRER, J. (1987) La Grana, un producto de la Economía del Marquesado de Villena. En Instituto de Estudios Albacetenses (editores), Congreso de Historia del Marquesado de Villena. 361-370.

SERRANO RODRÍGUEZ, E. (2012). Piedad, Nobleza y Reforma: la fundación del monasterio de la Madre de Dios de Toledo. Archivo Dominicano (33) 213-237.

TORAL PEÑARANDA, E (1994). Algunas observaciones sobre el discurso genealógico del linaje de los Aranda de Alcalá el Real. Boletín del Instituto de Estudios Giennenses (153) 915-945.

TORRES FONTES, J (1953). Don Pedro Fajardo, Adelantado Mayor del Reino de Murcia C.S.I.C.

VALENCIA RODRÍGUEZ, J. M. (1999). Las Encomiendas de Ordenes Militares. Revista de Estudios Extremeños (55) pp. 459-490. 